\title{
The Passionate Beliefs. A Defense of the Cognitive-Evaluative Theory of Emotions
}

\author{
Giulio Sacco ${ }^{1}$ (])
}

Received: 15 July 2021 / Revised: 20 September 2021 / Accepted: 23 September 2021/

Published online: 14 October 2021

(c) The Author(s) 2021

\section{Abstract}

The philosophy of emotions has long been dominated by the view called «cognitivism». According to it, emotions are characterized (and definable) not by mere physical impulses but by a cognitive evaluation of their object. However, despite their success, cognitive theories have to deal with various objections and are divided on how to answer to them. In this essay I want to defend the form of cognitivism claimed by Martha Nussbaum from the most common criticisms. After a brief summary of her account, I confront some of the objections that have been raised against it. In Section 2 I deal with the classic problem of emotions in infants and animals, which lack linguistic abilities. Later, I confront the potential problem represented by cases in which one's emotion and reasoned judgment seem to differ: in paragraph 3 I consider irrational phobias and fears, to show how they can be accounted for in terms of judgments and thoughts, and not only of perceptions; in paragraph 4 I deal with the objection that «judgementalist» theories (that is, those that describe emotions in terms of judgments and beliefs) violate the «principle of charity», for they ascribe an excessive irrationality to people. I argue that experimental evidence suggest that it is not implausible to assume that people have contradictory beliefs under conditions of uncertainty, and that perceptual theories of emotion (which compare emotional conflicts to optical illusions) fail to account for some fundamental aspects of these phenomena. Finally, in paragraph 5, I deal with the objection according to which a cognitive-evaluative theory cannot explain the sense of passivity that we commonly experience in emotions.

Keywords Emotions · Cognitivism $\cdot$ Cognitive-evaluative theory $\cdot$ Perceptual theory · Martha Nussbaum

Giulio Sacco

giulio.sacco@studenti.unipg.it

1 Department of Philosophy, Social Sciences and Education, University of Perugia, Piazza G.

Ermini 1, Perugia, Italy 
In the contemporary philosophical debate on emotions, the so-called «cognitivism» (Deigh, 1994) has become an influential theory. According to this view, which has gradually replaced the theory according to which emotions are irrational motions or impulses, one's emotional experience is closely linked to one's cognitive processes. In fact, in the second half of the Twentieth Century, an increasing number of scholars began to reject the James-Lange theory, which stated that emotions are subjective feeling of the bodily changes that occur in the face of an exciting fact, being nothing but physiological reactions (James, 1884). This account was already criticized by Walter Cannon (1927), who argued that the same bodily changes (such as acceleration of the heartbeat, increased sweating and similar) can occur both in very different emotions and in non-emotional states; moreover, he also showed that, if physiological reactions normally associated with certain emotions are artificially induced in someone-for example through the injection of adrenaline-they do not automatically feel the corresponding emotions. ${ }^{1}$ These evidences have driven philosophers and psychologists to increasingly recognize that emotions are characterized (and definable) not by mere physical impulses but by a cognitive evaluation of their object. ${ }^{2}$

Despite the success of the cognitive perspective, however, the debate is still animated by profound disagreement. Indeed, as some have pointed out (Deigh, 1994), cognitive theory raises some issues and has to deal with various objections. Furthermore, the way of replying to them divides the same cognitivist philosophers, who disagree on the fact of defining the cognitive component of emotions in terms of perceptions or «construals» (view that has enjoyed a favorable reception in recent years), or in terms of judgments, thoughts and beliefs. In this essay I want to defend Martha Nussbaum's account of emotions, which represents one of the most compelling and well-known examples of this second type of cognitivism. After a brief summary of her perspective in the first paragraph, I will confront some of the problems that have been associated with her proposal. In Section 2 I will deal with the classic objection that the fact that infants and animals-lacking linguistic abilities-can also experience emotions would refute Nussbaum's theory. In paragraphs 3 and 4 I will confront the potential problem represented by cases in which one's emotion and reasoned judgment seem to differ: in paragraph 3 I will consider irrational phobias and fears, to show how they can be accounted for in terms of judgments and thoughts, and not only of perceptions; in Section 4 I will deal with another kind of criticism, dwelling above all on the accusation that «judgementalist» theories (that is, those that describe emotions in terms of judgments and beliefs) violate the "principle of charity», for they ascribe an excessive irrationality to people. I will show that the

\footnotetext{
1 The thesis that the induction of bodily changes is not sufficient to elicit an emotion in the subject was then also experimentally verified by Schachter and Singer (1962). They injected some students with adrenaline, inducing a state of activation in them. However, although the physiological changes were the same, the subjects felt cheerfulness or anger depending on how they assessed the situation (in the first case they were seated in a room with a stooge who joked and played, in the second they were asked to fill out an irritating questionnaire towards which the actor angrily showed contempt).

2 See, for instance, Lazarus, 1991 and Lazarus \& Lazarus, 1994. Prinz (2004) is one of the last who still defend the James-Lange theory, claiming that emotions are perceptions of somatic changes.
} 
refusal to assign contradictory beliefs to someone in situations of uncertainty is the result of a prejudice, and is disproved by experimental evidence; moreover, I will argue that perceptual theories of emotion (which compare emotional conflicts to optical illusions) fail to account for some fundamental aspects of these phenomena. Finally, in paragraph 5, I will deal with the objection according to which a cognitive-evaluative theory cannot explain the sense of passivity that we commonly experience in emotions.

\section{The Cognitive-evaluative Theory: Nussbaum's Account of Emotions}

The theory proposed by Nussbaum can be defined as «cognitive-evaluative». Developing some suggestions from the experimental psychological investigation, she argues that emotions are intentional, that is, they are about an object (a thing, a situation, a person, etc.) that we understand, or judge, in a certain way (as positive or negative, useful or harmful, valuable or not) in relation to our most pivotal ends. In this sense, Nussbaum claims that emotions are eudaimonistic, to indicate that they contain a judgment on the importance of certain external goods for one's own happiness, or flourishing (as she translates the Greek eudaimonia). More specifically, Nussbaum's (2001: 34) account rests on three main statements: 1) «the relevant beliefs [are] constituent parts» of our emotions; 2) «having such beliefs [is] a necessary condition for having the emotion in question»; 3) «having such beliefs [is] a sufficient condition for having the emotion in question». This means that, according to her, one cannot experience emotions without having certain judgments; and that-vice versa-it is impossible to have certain thoughts without them being accompanied by the corresponding emotions.

The first two sentences are generally accepted-albeit in sometimes quite different forms-in the contemporary philosophical debate (but they are also at the basis of the thought of classics such as Aristotle, Seneca and Adam Smith). The experimental works mentioned above argue in their favor, and even reflection on our daily experience reminds us that it is difficult to describe our emotions without referring in any way to some kind of thought and evaluation about their object. Furthermore, it is clear that, unlike appetites such as hunger and thirst (which are, indeed, bodily pushes), they are reactive to our changes in the way we see things: it is possible-although not always easy-to convince an angry or frightened person to stop feeling this emotion; conversely, even the most clever speaker could not persuade a hungry or thirsty person that he/she is not. This has led most philosophers to acknowledge the importance, in emotional phenomena, of some form of cognition and evaluation-disagreeing solely on what, more precisely, this cognition is: a belief, a judgment, a form of perception or a «construal» (I will confront some of these alternatives in the next sections).

There is more disagreement about her third statement, i.e. that not only are judgments part of what an emotion is, but they are also a sufficient condition for it, so that emotion can be defined by referring only to them. This claim finds the opposition of those, even on the cognitivist front itself, who think that a detailed account of emotional life cannot overlook the role of feelings and/or other non-cognitive 
elements. ${ }^{3}$ The reasons that lead Nussbaum to take this last step are mainly three. First of all, there may be persistent emotions, which last for a long time and are not associated with any sensation: for instance, most people have, throughout their life, fear of death without experiencing feelings, like trembles or shivers, that are typically associated with it. Someone could argue that the problem of persistent emotions can be overcome by distinguishing between acute, or short term, emotional episodes and longer-lasting sentiments. Aaron Ben-Ze'ev (2017: 1545-1546), for instance, analyzing the temporal aspects of emotional experience, distinguishes between acute, extended and enduring «affective attitudes», where each one lasts longer than the previous. Previously, he Ben-Ze'ev (2000: 82-86) had distinguished between emotions, emotion episodes (that is emotions «lasting intermittently for an extended period of time») and sentiments, which are more stable and long-lasting. Whereas acute emotions are actual states, sentiments, or enduring emotions, have a «dispositional» nature: they are in the background of people's affective experience, and make them inclined to experience certain emotions. Furthermore, they shape present attitudes and behavior, influencing one's habits. ${ }^{4}$ A similar distinction, based on the duration of the phenomenon, is that between «reactive emotions» and «sentiments» used by the psychologist Keith Oatley (2004: 4). These kinds of analyzes are subtle and can help make the account of emotions more detailed. Nevertheless, it seems to me that they do not solve the problem of the absence of feelings since the very sentiments are defined as a type of emotion, just longer lasting. ${ }^{5}$

Nussbaum's second reason for the condition of sufficiency is that it is not possible to isolate a pattern of sensations that systematically occur along with a certain emotion. It could be objected that every time we are excited we feel something related to our bodily changes; but, notes Nussbaum (2001: 58), «all human experiences are embodied, and thus realized in some kind of material process». The point is that, according to her, feelings do not characterize our emotional experience, but at the most they accompany it without defining its identity. Some might argue that this does not exclude the possibility of identifying groups of sensations typically associated with certain emotions, or that, to experience some emotions, it is necessary at least to exceed a minimum threshold of physical arousal. Nussbaum replies by insisting on the great variability of the ways in which emotions manifest themselves in different subjects. Even emotions such as anger, associated by many people with a feeling of inner fire and energy, present themselves in a variety of different ways: Nussbaum claims she experiences it, like many women, as a severe headache; and in my life I have even met someone who cries when they get angry. Yet, despite the different physical sensations, we consider ourselves entitled to say that these people feel anger. And even assuming, for the sake of argument, that it turns out that some

\footnotetext{
3 See, for instance, Ben-Ze'ev (2000, 2004).

4 Ben-Ze'Ev (2017: 1543-1544) distinguishes three senses in which persistent emotions are dispositional: 1) they are subject to repetition; 2) they can be «actualized in the sense of moving from the background of the affective experience to its foreground»; 3) they have «an inherent potential to develop».

5 Ben-Ze'Ev (2000: 82) writes that «[e]xtended emotion episodes become sentiments». For Oatley (2004: 4), sentiments are «long-lasting emotional states of relating to other people».
} 
feelings always accompany certain emotions, I think that the condition of sufficiency would remain plausible in one sense: as I will show in Section 3, if one has certain beliefs, they cannot help but feel the corresponding emotion (and, in case, any sensations that occur systematically together with it).

Despite this, it may continue to seem counterintuitive to bear that thoughts are sufficient to experience and define an emotion. Ben-Ze'ev (2004: 453-456), for instance, argued that Nussbaum fails to indicate a reliable criterion for distinguishing cold deliberation from the emotional one, since all the elements she indicates as typical of emotions (the fact that the judgment must concern those that the subject considers its most important ends, and that it must contain a rich and dense perception of the object) can also occur in normal intellectual deliberations. According to him, although it is plausible that the most direct and determining cause of many passions are evaluative judgments, it is impossible to distinguish the emotional experience from the («cold») rational one without making any reference to non-cognitive components. However, it seems to me that Ben-Ze'ev does not approach the issue from the right perspective: if, in fact, we analyze in detail the typical judgments of each emotion, it emerges that it is impossible to support all the beliefs in question without experiencing, at the same time, any passion. Taking up the example of mourning, Nussbaum (2001: 40) asks: «Can I assent to the idea that someone tremendously beloved is forever lost to me, and yet preserve emotional equanimity?». Is it possible to think that a person (currently) central to one's eudaimonia is missing and at the same time feel totally indifferent? It definitely seems not. If someone supported it, we would, plausibly, be faced with some form of insincerity.

It is true that one of the standard ways psychologists use to classify emotions is just to refer to «valence», that is, to the fact that they are experienced by the subject as pleasant or unpleasant. But it is pivotal to consider carefully the nature of these pains and pleasures involved in emotions. This is exactly Nussbaum's third argument. Let us take mourning: is the pain associated with it simply «a fluttering off in her ear, or a trembling in her stomach? Is it a movement in some animal appetitive nature that she shares with rabbits and birds? No» (Nussbaum, 1994: 379). It is, conversely, a mental pain, «namely, the pain that an important element of one's life is gone» (Nussbaum, 2001: 64). It is not a physical pain, other than judgment: it is the judgment itself that represents pain. Therefore, it makes no sense for Nussbaum to claim that pain (or pleasure) is a non-cognitive element, extrinsic to judgment, without which it would not be distinguished from «cold» rational deliberation.

These remarks also lead her to a further conclusion: that emotion can be identified with the judgment itself. In fact, following Stoic thinking, she defines judgment as the operation of assenting (or disagreeing) to an appearance. But, she argues Nussbaum (2001: 45), «[w]hen I grieve, I do not first of all coolly embrace the proposition, "My wonderful mother is dead", and then set about grieving. No, the real, full recognition of that terrible event (as many times as I recognize it) is the upheaval». As someone has noted (Ben-Ze'ev, 2004), this is the most questionable part of Nussbaum's theory, since, even accepting that the cognitive-evaluative component is what allows us to distinguish one emotion from another, and that characteristic beliefs of an emotion are sufficient to differentiate it from a non-emotional experience, this does not authorize us to sustain its identity. The defense of a 
cognitive-evaluative theory does not compel us to commit ourselves in this last step. However, I find that, when read correctly, Nussbaum's general approach is plausible: our emotional experience is characterized by evaluative thoughts about what we consider central to our well-being. To test the strength of this account, it is now necessary to confront some standard objections to cognitive theories, and analyze whether it can answer convincingly (both with reference to our daily experience, and to other rival models).

\section{Some Objections to the Cognitive-evaluative Theory: Emotions in Beasts and Infants}

As John Deigh (1994: 846-852) pointed out in his valuable account, while feelingcentered conceptions have difficulty to explain the intentionality of emotions and the fact that they can be object of rational assessment (i.e. they can be considered rationally correct or incorrect, appropriate or inappropriate), cognitive theories are open to two main types of objections: that even non-human animals and infants, who lack linguistic faculties, experience emotions; and that it seems possible, sometimes, to experience an emotion without supporting the corresponding belief that is usually associated with it. Both of these criticisms have been advanced to Nussbaum's theory, which however-we will see later-, compared to other cognitivist approaches, is also subject to a third attack, that is to fail to account for the sense of passivity that people often experience in their emotional states.

The first challenge that any cognitive theory must face is to explain what Deigh (2004: 10) calls «primitive emotions», i.e. those emotional experiences, such as anger or fear, that humans seem to share with animals. Indeed, since it is clear that they too manifest these emotions, despite their lack of capacity for propositional thinking, this could jeopardize the idea that emotions are a form of (or derive from) evaluative judgment of a fact or event that we consider pivotal from our point of view. As Robert C. Roberts (1996: 153-154) has argued, when, for instance, a rabbit is frightened by the sight of a snake, it is difficult to believe that its reaction comes from the thought that it is dangerous, since «danger» is a linguistic concept that perhaps no animal possesses. Furthermore, we have strong evidence that fear is an incredibly primordial emotion, also shared by animals with a rather simple cognitive structure, such as rats and mice (LeDoux, 1996; Nussbaum, 2012: 20-29, and Nussbaum 2018: 23-31). For this reason, some cognitivist philosophers prefer to ignore the passions of beasts and focus only on human ones, in the belief that the former are only sensations or mere automatic responses (cf. Deigh, 1994: 847-848). Otherwise, Roberts $(1988,2003)$ proposes to frame the cognitive dimension of emotions in a different way, avoiding referring to beliefs or propositional thinking: they should not be identified with judgments, but with «construals»-more precisely, «concern-based 'construals'»-, i.e. forms of perception in which an object is «seen» or grasped (rather than judged) in a certain way, with reference to one's concerns. According to the American philosopher, this account provides a better explanation of the rabbit's reaction, since, if it is unable to formulate a judgment, it can however 
«see» the situation as dangerous, also relying on certain sensory properties and organizing the data it has at its disposal (Roberts, 1996: 153-154).

Nussbaum's way of dealing with the issue is in some respects similar to that of Roberts, in others very different. While she too agrees on the need not to reduce cognitive activity to the exercise of language, she does not compare emotions to mere perceptions, but she does ascribe also to non-human animals the ability to have eudaimonistic and evaluative thoughts, although not expressed (or expressible) in propositional form, that is elaborated as complete meaning sentences. To be sure, it should be pointed out that sometimes Nussbaum's terminology tends to be more ambiguous, to the point of coming very close to that of Roberts'. This happens, for example, when she comes to define cognitive activity as «seeing $\mathrm{X}$ as $\mathrm{Y}$ » (Nussbaum, 2001: 34, note 29). She writes: «There are many kinds of cognitive activity or seeing-as in which ideas of salience and importance figure: there are pictorial imaginings, musical imaginings, the kinetic form of imagining involved in dance, and others. These are not all reducible to or straightforwardly translatable into linguistic symbolism» (Nussbaum, 2001:127-128, my italics). Moreover: «What we need, in short, is a multifaceted notion of cognitive interpretation or seeing-as, accompanied by a flexible notion of intentionality that allows us to ascribe to a creature more or less precise, vaguer or more demarcated, ways of intending an object and marking it as salient» Nussbaum (2001: 129, my italics). Hence, in practice, Nussbaum's position does not differ so much from Roberts'. ${ }^{6}$ However, beyond these terminological fluctuations, I find her account, which speaks of judgments and appraisals (although not always formulated in propositional form) rather than perceptions and «construals», more satisfying, for several reasons. I will explain the most important of them in detail in the next sections; for the moment, I will limit myself to saying that it is not inconsistent with current evidence, and that it is more respectful of the (admirable) intelligence that animals show.

It is true that sometimes some simpler animals exhibit automatic behaviors when faced with some physical characteristics. ${ }^{7}$ However, both experimental observations and everyday experience with different mammals show that in many cases they are capable of cognitively complex behaviors, which should not be underestimated. Nussbaum (2001: 100-106) cites Martin Seligman's (1975) empirical inquiry, which showed that the behavior of dogs is led by sophisticated assessments about their ability to control the environment and to positively affect their well-being through their own actions. ${ }^{8}$ She Nussbaum (2001: 119-125; Nussbaum 2013: 147-155) also

\footnotetext{
${ }^{6}$ Indeed, also Robert Solomon (1984: 408) pointed out that, ultimately, what he means by «judgments» has much in common with Roberts' «construals»: «what he calls "construal", I call a "constitutive judgment". I characterize this, as he does "construal", in terms of "seeing-as", "thinking-as", etc.»

7 See, for instance, Fox, 1974.

8 In detail, Seligman placed the dog in a cage divided in two by a barrier, called the shuttle box. When a light signal was turned on, an electric shock was produced in the part of the cage where the animal sat, which the dog could escape by jumping to the other side. Under normal conditions, dogs quickly learn to avoid shock. However, the experiment has a very different outcome if they are previously tied, so as to be completely unable to react to shocks: after passively suffering a certain number of discharges, the subjects are left free again inside the shuttle box; however-unlike other dogs, free to move from the start-they are unable to learn how to escape, remaining completely apathetic and passive in the face of
} 
recalls some observations and direct experiences of animal intelligence: one is that of the ethologist Cynthia Moss (2000: 72-74), who described the evidently grieved behavior of a herd of elephants upon the death of a young female in the group. Another is George Pitcher's autobiographical account of his life with the two dogs Lupa and Remus: he portrays several of their behaviors that suggest their ability to evaluate a situation as positive or negative (for example, in their attempt to console the philosopher who was crying in front of the TV, by licking his face). In general, it is no exaggeration to claim that anyone who has at least a little familiarity with animals knows that, although they do not have linguistic capacities, they can judge the events they experience and elaborate more or less complex thoughts: it is undeniable that in some cases they feel hope, and that they are able to form expectations (as it is clear to owners who see their dogs joyful at the sight of the leash); several studies show that some of them are capable of causal thinking (Schloegl \& Fischer, 2017); and someone even supposes that they possess proto-religious thinking (Kehoe, 2016). Hence, it seems far from unreasonable to grant that they are able to make assessments about the importance of a situation or a thing for their own well-being.

Someone might find it problematic to maintain that animals are capable of evaluative judgments. Paul Griffiths (2004: 243-247), for instance, claimed that those of animals are only «low-level appraisals», which therefore do not deserve to be called «judgments». From a somewhat similar perspective, Roberts (2009) argued that the best way to account for both the continuity and discontinuity between human and animal emotions is to distinguish possessing «concepts» from possessing «thoughts». According to his vision, we can speak of «concepts» to indicate the systematic ability to recognize things in terms of their functions, to distinguish them from one another and to relate them to each other. Having «thoughts», instead, denotes the ability to isolate a concept-understood as Roberts'-from its perceptual context and use it in a more abstract way: consider it reflexively, compare and relate it to other thoughts. Insofar as having concepts is a necessary condition of perception-Roberts states-animals possess them, while they are devoid of thought, which is inextricably linked to language. Thus, they are able to distinguish between a dangerous and a safe situation for their well-being, between hostile and friendly behavior; but it is far-fetched to think that they are capable of detaching these characteristics from the perceptual context in which they occur.

Roberts' (2009) account of the different levels of sophistication of human and animal emotions is ingenious and, relying on the experimental work of ethologists, succeeds in many respects to do justice to the admirable abilities of animals. However, in my opinion, it suffers from some problems. First, the terminological distinction he proposes seems somewhat arbitrary. The term «concept»-at least in ordinary

\footnotetext{
Footnote 8 (continued)

discharges. Only after the researchers show them how to avoid the shock, carrying them in their arms to the other side of the barrier, can they learn for themselves how to escape. Seligman's explanation (also verified with rats and humans) is that the perception of one's own helplessness produces a depression that leads the subject to apathy: when the dog thinks he can do nothing to change his situation, he falls into an inert liability. If, on the other hand, he is given even the slightest chance to influence the severity of the shocks (even, for example, standing still) he does not become apathetic. These results show that dogs are capable of elaborating sophisticated assessments of their ability to improve their condition through their actions.
} 
language-does not seem to suggest a lesser degree of cognitive complexity: «formulating a concept» even seems to imply a greater sophistication than simple thought. Usually, we say that people have vague thoughts about justice, while philosophers try to make them stricter by elaborating more rigorous and coherent concepts. The Nobel laureate Daniel Kahneman titled his psychological bestseller on cognitive biases Thinking, fast and slow. In his terminology, when we use mental shortcuts, heuristics and automatic (even unconscious) responses, we are «thinking fast». Of course, this does not mean that Kahneman's vocabulary must represent the ultimate philosophical classification. However, it is instructive to note that in ordinary language (and in brilliant scholars' intuitions) the word «thought» is not at all linked to a more sophisticated activity than having a concept. Secondly, the strenuous attempt to find a clearcut separation between animal and human mental processes (even when their behavior would lead us to recognize them as possessing a rich cognition) seems to be exactly what the ethologist Frans de Waal (2006) defines «anthropodenial», i.e. the ideological refusal to endorse other animals with traits similar to humans. Finally, although Roberts' view may appear to some more compelling with reference to the explanation of animal emotions (as it indulges the need to find a clear separation between human and animal mental processes), it is problematic-like other perceptual theories-when it comes to accounting for recalcitrant emotions, as I will argue in Section 3 and 4.

A different objection to Nussbaum's view was raised by John Deigh (2000: 303-305), according to whom, strictly considering her account of judgment as assent given to an appearance, it is not clear how this process can be attributed to animals, as this would imply that they were endowed with the (abstract) idea of true and false, real and unreal. I find it unnecessary to describe judgments as forms of assent or dissent to an appearance in order to support a coherent account of emotions as judgments; but, in any case, Nussbaum (2000: 361) has convincingly replied that, while animals and infants are clearly less reflective than adult humans (and this affects their emotional life), they can indeed reject some appearances: for instance, «some higher animals can learn that a person who seems frightening is really benign, or that one who seems benign is really cruel [...]. This will feed into their view of appearances, and they will reject the appearance "This is a nice man"». Therefore, the objection of the passions in animals and infants does not refute the account of emotions as beliefs or judgments of value, since it is not certain that thinking and evaluation skills are limited to linguistic creatures. ${ }^{9}$

\section{Conflict between Emotions and Reason I: Phobias and Irrational Passions}

The second problem that a cognitivist theory has to deal with is the phenomenon that Michael Brady, following D'Arms and Jacobson (2003), defines «recalcitrant emotions», that is, those situations in which the subject feels an emotion without

\footnotetext{
9 Solomon (1988: 185-186) raised a similar criticism to Roberts and his other opponents: namely, that judgments need not necessarily to be understood as propositional attitudes.
} 
supporting the corresponding belief. In these cases, the emotion persists despite the fact that the subject has, apparently, formulated a judgment that is in contradiction with it. ${ }^{10}$ I will address this issue from two different points of view: in this paragraph I will deal with the objections that appeal to phobias and irrational passions, to explain how these phenomena can be perfectly understood in the cognitivist perspective I have supported so far; instead, in the next section I will confront a parallel problem, i.e. the assertion that the cognitivist account that I will defend in the following pages does not respect the so-called «principle of charity», insofar as it ascribes an excessive degree of irrationality to the subjects.

A paradigmatic example of the first type of objection came from the aforementioned Roberts, who criticized Nussbaum's identification of emotions and judgments. He argues that: a) the subject does not always support the characteristic propositional content of the emotion; and that b) it is possible to sustain a judgment usually associated with a certain emotion without experiencing it. In fact, according to Roberts (1999: 795), it can happen that «[t]he subject's judgment» differs from «the emotion's "judgment"» (although they often overlap), as happens for perceptions, to which we do not necessarily always listen. Likewise, one may think, for instance, that one's anger is unjustified, and yet continue to be angry. The tendency to think that emotions are forms of belief derives, for him, from «confusing what the emotion "assents" to with what the subject of the emotion assents to» (Roberts, 1999: 796; my italics). On the contrary, Roberts states that it is not inconsistent to imagine that an acrophobic (who is afraid of heights) thinks that heights do not represent a real danger to his survival, and yet he continues to fear them irrationally. As mentioned earlier, he explains this by defining emotions as «construals», comparing them to forms of perception.

It seems to me that Roberts' description does not fit our common emotional experience. I find it hard to imagine a person being angry with someone without thinking that they have harmed or offended them in some way. ${ }^{11}$ What can happen is that, for many reasons, one thinks that it is inappropriate to express their anger, and therefore tries to contain themselves, like an employee who refrains from expressing his anger at the annoying complaints of his boss. However, if someone considers it improper to show their emotions, it does not mean that they think their anger is unwarranted. Rather, insofar as they are really angry, they will think they are right (that is, that someone has inflicted unjustified harm on them). It could also happen that, by virtue of an education that stigmatizes anger, one feels guilty for being angry, and therefore tries somehow to calm down and not think about the offense; or perhaps they are ashamed to take these things seriously while others would not. ${ }^{12}$ But again, this does

\footnotetext{
${ }^{10}$ Brady 2007, 2009. Nussbaum (2001: 85) calls this phenomenon «emotional conflict».

${ }^{11}$ Developing some insights contained in Aristotle's Rhetoric, Nussbaum (2016: 17-21) convincingly argued that anger consists of three main cognitive elements: the idea that someone has harmed us or a person we care about (what Aristotle defined offense, oligöria); the awareness that such outrage is unfair or undeserved; a retributive thought, i.e. the desire to return the damage to one's offender as compensation and / or new attestation of the self.

${ }^{12}$ Social pressure often pushes people to feel ashamed of having ideas that are considered to be wrong by the majority, and therefore to silence their doubts (on this issue, see the experimental inquiry conducted by Asch, 1955).
} 
not mean that, while they are angry, they do not have the typical thoughts of this emotion. (In my whole life, I have never met anyone who gets angry and, at the same time, thinks that they have not suffered any wrong or harm: this is precisely why it is not easy to persuade an angry person that his/her reaction is exaggerated.) A similar reply can be opposed to the case of the acrophobic. As Nussbaum often argues in response to such objections, it is necessary to distinguish those beliefs that we support in a, we could say, "nominal" way (that is, only superficially, or facade) from those that we have really internalized. These experiences just show how difficult it can be to really get rid of a certain thought when it has been internalized-especially when it comes from early childhood. (I will return to these issues in paragraph 5, dealing with the feeling of passivity often associated with emotions, and in paragraph 4 , responding to the objection that this explanation is circular.)

A perfect example of what I have said can be found, paradoxically, in the words of Peter Goldie (2000) who, analyzing a case of emotional conflict, intended to refute the cognitivist position, guilty, according to him, of «over-intellectualization of emotion» (Goldie, 2000: 22). He imagines someone who, after being in therapy to treat the fear of flying, continues to be scared:

«After successful cognitive therapy you might believe to a high degree of probability that flying on scheduled aircraft is very unlikely to result in injury or death, yet flying can still seem to you to be terrifying - you still feel fear. When you hear a change in the aircraft's engine noise, or feel a bump as the wheels are lowered before landing, a wave of fear overwhelms you: you grasp the sound as the sound of an engine in trouble, and the bump as that of something failing to work properly. You look for signs of worry in the faces of the flight attendants, find yourself imagining the panic as the aircraft goes into a dive, and the other passengers trampling you underfoot as they rush towards the emergency exit. Yet at the same time you can be struggling to keep your imagination under control, talking to yourself and reminding yourself of your persistent beliefs: 'No, the engine noise always dips like this on descent; there's always a bump like this when the wheels are lowered'» (Goldie, 2000: 77, my italics).

Goldie's explanation is that emotions are not only the product of one's beliefs but also of one's feelings (which he defines «feelings towards», to indicate their intentional character and distinguish them from sheer «bodily feelings»). The problem with his instance is that, on the contrary, it portray emotional conflict precisely in cognitive terms: a person seeks to reassure himself, trying to self-convince himself that he is safe. But then he «grasp[s] the sound as the sound of an engine in trouble»; he «look $[s]$ for signs of worry in the faces of the flight attendants»; he «imagin $[e s]$ the panic as the aircraft goes into a dive»; hence, he is afraid. (Notice that he becomes so after a series of thought activities, which lead him to the conclusion that the situation, although he would like to believe otherwise, is dangerous.) The same terminology used to describe these emotional events shows that it is not possible to describe someone's emotions without referring to their beliefs.

As I have already mentioned, Roberts holds that it is not only possible to experience an emotion without supporting the corresponding belief, but also that the 
reverse case occurs, i.e., that the person maintains a certain judgment without having, despite this, the corresponding emotion. Taking up an example of Nussbaum (1994), he imagines the mourning of a girl who has lost her beloved: at first, she is deeply saddened by his death; but, over time, she overcomes mourning, and no longer suffer as before. According to Roberts, her grief disappears even though she still loves her deceased partner, because what has changed is not her judgments but the impressions or perceptions she has of him. The explanation that Nussbaum (1994: 375-386; Nussbaum 2001: 79-85) suggests, reworking some of the intuitions of the stoic Chrysippus, is instead that mourning vanishes when the subject learns to recalibrate her network of beliefs and expectations (e.g., that she will see her beloved again in the evening or in the following morning, or that she will be able to talk with him). Roberts (1999: 797-798) disagrees with this claim, for he holds that, if the girl is a rational person, she will stop having these thoughts long before the grief disappears. This answer, however, seems to me to misunderstand the meaning of Nussbaum's statements. When she speaks of the recalibration of expectations, she means something more than the simple recognition of the death of the other: she instead means that, if initially the mourning deeply upsets one's personal existence, over time the subject learns to live with the absence of the loved one, finding other sources of happiness to move forward. In this sense, when the loss is long on and the grief is over, it can no longer be said that the missing person is still central to someone's life: the subject would say that it was, but it is no longer so (that is, it is no longer at the center of its projects, aims and ends). This is what happens in cases of normal mourning (and which does not happen in cases of pathological mourning). And these changes are just changes in beliefs. ${ }^{13}$

In this section I have defended a cognitive explanation of emotional conflicts that is just as (if not more) convincing than opposing ones. I have shown that it is possible to account for these events not only, as others have done, in terms of perception, of construals (as Roberts suggested), or of «feelings towards» (as Goldie did), but in terms of beliefs, evaluations, judgments. In the next paragraph (§ 4) I will deal with a parallel (but perhaps more puzzling) problem: the objection according to which the account proposed in this paragraph, however conceivable, is not acceptable, since it would ascribe an excessive irrationality to the people who experience emotional conflicts, violating the «principle of charity».

\section{Conflict Emotions-reason II: The 'Principle of Charity' and the Challenge of Recalcitrant Emotions}

As mentioned, one of the central problems connected to the phenomenon of recalcitrant emotions is to explain in what sense they (and the subject who feels them) are irrational. The question was clearly expressed by Patricia Greenspan (1980: 161-162). She imagines someone who, due to the shock suffered after a violent attack by a dog, develops an irrational phobia of all dogs, and even fears

${ }^{13}$ For Nussbaum's direct reply to Roberts, see also (Nussbaum, 1999: 814-815). 
the harmless Fido, the old toothless dog of one of his friends, despite being aware that it is not dangerous. Nussbaum's explanation, which I defended in the previous paragraph, is that in some situations there is a fluctuation between the subject's beliefs; but, finally, our emotion matches the belief that is strongest in us. Indeed, Nussbaum (2001: 35) claims, «we may often hold contradictory beliefs, especially in cases involving long habituation». Now, Greenspan bears that such an account violates the principle of charity, insofar as it attributes contradictory beliefs to people on too many occasions:

«Logical incoherency is possible, of course; but I am assuming that the agent is functioning quite rationally in general, so that our ascription of beliefs to him ought to be governed by a principle of "logical charity". We need some special reason, that is-of a sort that I shall try to indicate laterfor attributing to him an unacknowledged judgment in conflict with those he acknowledges» (Greenspan, 1988: p. 18; cf. pp. 17-20).

For these reasons, some authors have tried to develop perceptual theories, even very different from each other (think of those of Michael Brady, Robert Roberts and Sabine Döring), which-linking emotions to perception-compare these cases of conflict with optical illusions, such as the bent stick in water or the MüllerLyer illusion. The latter represents two lines of the same length, placed one above the other, which are seen by the subject as different since one ends with two segments that form an acute angle, the other an obtuse one. In both cases, we may be well aware of how things really are (i.e., that the stick is not bent, and the lines are equally long), but this does not change our perception, which remains distorted and contradicts our own stronger beliefs. In this way, cases of recalcitrant emotions can be explained without ascribing excessive irrationality to those who experience them, as happens in the theories that Brady (2009: 414) calls «judgementalism».

It seems to me that these accounts raise two sorts of criticism: first, they assume a wrong premise, which excludes a priori the possibility that people have inconsistent beliefs; secondly, they do not fully respond to our ordinary experience of such conflicts, which we commonly consider irrational, and which, instead, do not appear so in these portrayals. The first objection rests on the idea that these accounts confuse a simple regulative ideal (total coherence) with the reality of the facts. It is clear that all people who want to lead an examined life seek to aim for this ideal, but it is debatable whether it is really possible to achieve it. Indeed, we are often willing to live with some level of inconsistency, especially until we engage in deeper reflection. Distinguished psychologists have pointed out that many of our attitudes in the economic sphere are irrational, in the sense of inconsistent. In some famous experiments, Daniel Khaneman has shown that, faced with the same problem, people's choices are influenced by the way in which it is described. Consider the following problems:

Problem 1. You have won $\$ 200$. The casino now offers you the choice between (A) a sure gain of $\$ 50$ and (B) a $25 \%$ chance of winning $\$ 200$ and a $75 \%$ chance of winning nothing. 
Problem 2. You just won $\$ 400$. You are now asked to choose between (C) a sure loss of $\$ 150$ and (D) a $75 \%$ chance of losing $\$ 200$ and a $25 \%$ chance of losing nothing.

Notice that, although formulated differently, the two scenarios are identical, since the results of conservative choices (A) and (C), and of risky ones (B) and (D) are the same: «Choosing the sure gain in the first problem yields a total gain of \$200 plus $\$ 50$, or $\$ 250$. Choosing the sure loss in the second version yields the same result through the deduction of $\$ 150$ from $\$ 400$ [that is, \$250]. The choice of the gamble in either problem yields a 75 percent chance of winning $\$ 200$ and a 25 percent chance of winning $\$ 400 »$ (Kahneman \& Tversky, 1982: 166). However, despite this, most people choose option A in the first problem and option D in the second. Kahneman and Tversky (1979, 1982; Tversky \& Kahneman, 1981, 1986) have defined this phenomenon as «framing effects», to point out that the way in which the same problem is presented (that is, the way in which the question is formulated) influences people's response. But, since the two problems are the same in objective terms, preferring an option in the first case and the opposite one in the second is de facto equivalent to having contradictory beliefs, i.e. to think that a certain result is more desirable and, at the same time, less desirable. ${ }^{14}$ Similar paradoxes are the outcome of many psychological studies and have highlighted the failure of the expected utility model in predicting many choices in the economic field. ${ }^{15}$ But what matters to our investigation is that they suggest that we should not think of coherence-as some philosophers and economists tend to do-as a solid fact, but as a regulative ideal that sometimes (more or less often) people can violate. Furthermore, it should be emphasized that cases of emotional conflict does show, rather than a real inconsistency, a fluctuation between one judgment and another: on such occasions, typically, we feel torn between two rival worldviews; and what ultimately prevails is the basis of our emotional response.

This evidence should make cautious those who think that, by virtue of the principle of charity, we should exclude a priori the idea that emotional conflicts represent conflicts between beliefs or judgments. Furthermore, the perceptual theories of emotion also have a second limit, acutely highlighted by Bennett Helm (2001: 41-46): they fail to explain the irrationality of recalcitrant emotions. Indeed, while everyone agrees that these phenomena are irrational, optical illusions clearly are not. If someone is afraid to fly but at the same time claims to believe that planes are safe, it makes sense to accuse them of irrationality and ask them not to be afraid (or

\footnotetext{
14 The researchers generally asked the questions to distinct groups of respondents (selected from the brilliant minds of prestigious Universities), but-as every novice psychology student experiences-, until the "trick" is revealed, even the same person is led to choose the contradictory options in the two different formulations. Another well-known formulation of the «inversion of preferences» phenomenon refers to the production of a vaccine against a new disease, posing the same problem first in terms of how many people will survive and then how many people will die. I preferred to report the gambling version, for it is based only on numbers, while-where human lives are at stake-some philosopher could justify the results of the experiment by appealing to the distinction between actions and omissions.

15 On this point, see also the Nobel laureate Maurice Allais (1953).
} 
stop saying that planes are not dangerous). Conversely, this is not true for optical illusions: we would never ask anyone to see Müller-Lyer lines of the same length, since they know that this is so. Such a request would not make sense, while the other would. Perceptual theories struggle to fully account for this difference, without forcing interpretations.

Michael Brady sought to correct these issues by looking for an explanation of what it means, from the point of view of a perceptual theory, that recalcitrant emotions are irrational. He argues that the role of emotions (which made them evolutionarily important) is to capture and keep our attention fixed on their objects, facilitating a more accurate representation of them (e.g., danger, insult, loss, etc.). Hence, «emotions involve perceptions of value, but in addition they facilitate additional processing of the very perceptions that they involve» (Brady, 2007: 279; cf. pp. 278-280), drawing our attention to certain emotional stimuli, potentially important for us. But-Brady bears-, if we accept this account, the reason why recalcitrant emotions are irrational is that they represent a misperception of value, that is, they force the subject to direct his attention on an object that has previously been judged not relevant to him, leading to a waste of attentional resources. In other words, recalcitrant emotions are irrational in the sense that they «involve the mobilization of attentional resources in the service of a question that has, by the subject's own lights, already been answered; they are the emotional equivalent of preparing for an interview that one has already had, or of training for a race that one has already run» (Brady, 2007: 281).

However, it seems to me that Brady's way of accounting for recalcitrant emotions doesn't really hit the mark. It vaguely recalls Charles Stevenson and other emotivists' attempt to forcibly translate moral language into something substantially different (i.e., the expression of attitudes, desires, emotions): when we say that a person's fear of flying is irrational, what we really mean is not that it steals attentional resources that they could put on other more important objects. Rather, we do want to say that the person has no reason to be afraid, and that they should abandon the behavior that manifests the (particularly internalized) idea that flying is dangerous. In my opinion, this is similar to when we tell an intelligent person that it is stupid to be superstitious, because they should know that superstition is false, and therefore they should behave according to this truth. Likewise, when we tell someone that their fear is irrational, we are inviting them to truly believe that a certain fact or event is not dangerous, and therefore to behave accordingly.

The same type of objection can be raised towards Sabine Döring (2014), who argues that when we define recalcitrant emotions as irrational what we actually mean is only that they interfere with the pursuit of some of the goals that we rationally set ourselves. In this sense, they would not be different from optical illusions: simply, «recalcitrant emotions interfere to a much greater extent with the reasoned pursuit of our goals than recalcitrant perceptions because, by contrast with perceptions, emotions have motivational force» (Döring, 2014: 128). For instance, fear of heights can hinder my project of climbing a mountain, depriving me of a possible pleasure. Again, however, this explanation is too far from our common experience: first, even perceptual illusions can prevent us from achieving our goals (for example, seeing a bent stick in the water can hinder a lifeguard trying to clean the bottom of 
a swimming pool); secondly, we also consider as irrational those emotions that do not interfere with a person's life, simply because they are based on incorrect beliefs or assessments. (Think of the indomitable Gauls of the comic «Asterix», whose only fear is that the sky will fall on their heads: in spite of this fear, they remain brave heroes and their existence is not affected at all; yet we cannot help but smile at this silliness, since we know that such a thing cannot happen.) Hence, we can agree with Helm that the perceptual accounts are not adequate to explain cases of recalcitrant emotions.

However, Helm (2001: 39-40) also states that Nussbaum's theory is equally inadequate to explain the emotions-reason conflicts. As I have already mentioned, in fact, her strategy is to distinguish between judgments that we support only superficially ( $\mathrm{a} \ll[b]$ are assent to an evaluation») and judgments that we have fully internalized (a «full assent to an evaluation»). But, according to Helm, the definition of these terms is circular, insofar as the only way to distinguish the former from the latter is to refer to the fact that some give rise to an emotion, while the others do not:

«The central difficulty for Nussbaum's account is similar to that for Marks': we cannot give an account of what it is fully to assent to an evaluation without a viciously circular appeal to the emotions. After all, full assent must be more than decisive assent with a clear (intellectual) appreciation of the implications (cf. Nussbaum's "realize ... its full significance"). What is needed, and what Nussbaum tries to get with her metaphors of assenting "with the core of my being", is that one feels the evaluation emotionally. Without a specification of how we are to understand such full assent non-metaphorically, Nussbaum is simply begging the question» (Helm, 2001: 39-40). ${ }^{16}$

Helm's objections were directed to The Therapy of Desire (Nussbaum, 1994). In the subsequent Upheavals of Thought, Nussbaum clarified her position more clearly, partly reformulating her «metaphorical»-as Helm defines it-language. (In particular, she introduced the concept of «eudaimonistic judgment» to indicate that the beliefs and evaluations involved in emotions concern those objects-things, people, situations, etc.-which we consider central to our flourishing.) But Helm's argument remains a decisive challenge that, in my opinion, Nussbaum has not faced exhaustively. ${ }^{17}$ However, I believe that-while ingenious-it is not a severe threat to the cognitive-evaluative theory. The reason is that his objection applies, mutatis mutandis, to any beliefs and evaluative judgments (especially in the moral field). Let me try to explain why: when someone normally expresses a judgment of value, how can we assess their sincerity? The most reliable criterion-the only one, perhaps-to do so is what Bernard Williams (1973b: 221) defined «the criterion of appropriate action»,

\footnotetext{
16 Helm (1994: 321) holds that all classic cognitive approaches are doomed to beg the question. In fact, in order to distinguish cold deliberation from emotional experience, they argue that the judgments involved in the latter are of a special kind. But, «[w]hen we ask what it is that makes the relevant beliefs and desires special, the kind of specialness alluded to is not intelligible independently of the emotions themselves».

17 More recently, Andrea Scarantino (2010: 746) has also taken up this objection, arguing that, in this way, Nussbaum's proposal seems almost unfalsifiable.
} 
that is, to verify the «disposition on the part of the agent to do a certain type of action in certain types of circumstances». In other words, if a person professes a certain judgment of value, it is assumed that at least in some cases they are willing to act accordingly. If someone, for instance, claimed to consider superstition a stupid and degrading belief, a true insult to human intelligence, and then periodically consulted with a fortune teller, we would be entitled to conclude that they lied. Something similar can be said for our emotional responses: if one says they do not believe that planes are dangerous, while being fearful, it follows that-although they may wish to persuade themselves otherwise-in reality they are deeply convinced that flight is dangerous for their safety. Or, to return to the example of mourning, someone who claims to have lost a loved one, fundamental for their happiness, without being saddened, would be, in some sense, lying.

\section{The Sense of Passivity in the Emotional Experience}

We have seen how a cognitive theory, such as the one proposed by Nussbaum, can overcome the objections related to emotional conflicts and account for our daily experience better than rival views. At the end of this essay, I would like to confront the last challenge that is generally posed to this type of theory: the accusation of failing to explain the sense of passivity and uncontrollability that people normally experience in emotions. The fact that the subject sometimes seems able to control their emotions and sometimes not is presented by Roberts (1988: 192-193) as evidence that corroborates his «construals» theory, since, in his perspective, one's emotional change is explained in terms of a change in the way of «seeing» the situation-that is not always voluntary controllable.

Nussbaum (2001: 78) holds that the feeling of passivity in the face of one's own emotions derives from the nature of their objects, which are perceived as uncontrollable: «the experience of passivity in emotion is well explained by the fact that the objects of emotion are things and people whose activities and well-being we do not ourselves control, and in whom we have invested a good measure of our own wellbeing. They are our hostages to fortune. In emotion we recognize our own passivity before the ungoverned events of life». ${ }^{18}$ However, as noted by Lester Hunt (2006: 553-554), with whom I agree on this point, this explanation seems incomplete insofar as the passivity we experience in our emotions cannot be reduced to our lack of control of their objects. (The American scholar also adds that it is not always true that emotions focus on goods that we cannot govern: for example, when we are proud of having achieved an important triumph we feel powerful and effective, rather than fragile and vulnerable. I will not rely on this argument, as it is questionable whether we can really fully control our successes.) What Hunt wants to suggest is that this sense of passivity is closely related to the presence of non-cognitive

\footnotetext{
18 Also Gordon (1986: 384-385) claims that «most if not all of the states commonly classified as "emotions" are about states of affairs not presently under the subject's control. Not only are we acted on by something: we are acted on by something over which we have, at the time, no control». Hence, we experience «an attitude of helplessness».
} 
elements in our emotional experiences. This thesis takes up a long-running argument according to which the fact that emotions are experienced as passive, as something overwhelming that the subject cannot control, proves that they cannot be reduced to mere judgments. As, for instance, Richard Stanley Peters (1961: 119-120) wrote: "'Emotion', in the standard use of the term rather than in that coined by philosophers and psychologists, is used to suggest mists on our mental windscreen rather than straightforward judgments. Emotions, like the weather, come over us and one of their main functions is to distort and cloud judgment. Indeed if we say that a judgment is an expression of emotion we are suggesting that it is a pretty poor sort of judgment».

Nevertheless, I think that a cognitive theory can account for the experience of passivity of emotions: it is enough to consider the beliefs and judgments in the right way. In fact, these objections seem to assume that they are something totally voluntary, controllable at will; but they are not. There are many cases in which a person may want to believe something different from what he/she really thinks. Imagine, for instance, an intellectual who considers Satantango (Bela Tarr's famous arthouse film) a tiresome, senseless and pretentious film, but who-to be esteemed by his colleagues belonging to a circle of cinephiles-wishes to appreciate this sort of works. He would like to believe that it is a subtle and profound masterpiece, and get rid of the idea that it is frustrating and tedious; maybe he will also try to find out more, studying commentaries and specialist literature on the work, in the hope of being persuaded of its goodness. But despite these efforts and his desire to change his mind, he still thinks it is an overrated product. This example (and many others could be made) clearly demonstrates that one cannot fully control one's judgments and beliefs at will. ${ }^{19}$ This is even truer with the kind of thoughts involved in emotions. ${ }^{20}$ First, because they concern what we consider central to our flourishing; second, because some of the beliefs underlying emotions are internalized in childhood.

\footnotetext{
19 Also Bernard Williams (1973a: 147-148) has argued convincingly that, while we can decide whether or not to manifest our beliefs, we cannot decide which beliefs to have since-by definition-beliefs aim to represent reality. However, in his analysis, Williams focuses on factual beliefs-which could be limiting for an investigation into the passivity of emotions. Robert Solomon (1984: 407), for example, in responding to similar objections raised by Roberts, who noted that judgments cannot be decided at will, affirmed that « "objective" judgments of fact» cannot be compared to «subjective» ones that are involved in emotions («such as "judging myself to be inferior" or "judging you to be the most wonderful person in the world", judgments in which the "subjective" element is maximal and the correlation with any "objective" judgments of fact is tenuous at best, drop out of the picture»). Notwithstanding that it seems to me that even the former are linked to emotions, the instance I have proposed (the judgment on the value of a film) is not affected by this criticism.

20 As Robert Gordon (1986: 390) has ingeniously argued, the passivity of emotions derives from the fact that, unlike what happens for actions, where «a fully explicit reason for an action entails a positive evaluation of the action itself [...], a reason for an emotion such as gladness, embarrassment, or fear does not entail a positive (or negative) evaluation of the emotion itself, [but only] an evaluation of the "object" or "content" of the emotion». If, following Gordon's example, Mary thinks that the publicity of her wedding would be a terrible thing and a source of embarrassment for her, then she will positively evaluate any action she thinks can avoid this. On the contrary, if it happens that, having the same judgments, her marriage is effectively made public, this thought will produce the corresponding emotion of embarrassment; but it is clear that she would have preferred not to be ashamed. In this sense, we are passive in the face of emotions: we cannot control our thoughts and judgments, nor can we fully control the objects of our emotions.
} 
As Nussbaum (2001: 78-79) notes, «[o]ne prominent reason why emotions do feel, at times, like external energies not hooked up to our current ways of valuing and appraising is that they often derive from a past that we imperfectly comprehend». This explanation does not evade the problem of the passivity of emotions; on the contrary, I think it fully accounts for that sense of frustration and helplessness that is experienced when we cannot help but feel an emotion, even if we would prefer not to.

\section{Conclusion}

In this paper I have shown how a cognitive-evaluative theory of emotions, of the sort outlined by Martha Nussbaum, can answer some of the most common objections raised to it. None of these arguments purport to be conclusive, and to close such a fruitful discussion as the one that has developed in the philosophy of emotions. However, I hope to have succeeded in solving at least some issues, showing that a theory of emotions as judgments is no less adequate than a perceptual one to account for our experience; and that, indeed, it is better suited than others to explain significant aspects of our lives.

Funding Open access funding provided by Università degli Studi di Perugia within the CRUI-CARE Agreement.

Open Access This article is licensed under a Creative Commons Attribution 4.0 International License, which permits use, sharing, adaptation, distribution and reproduction in any medium or format, as long as you give appropriate credit to the original author(s) and the source, provide a link to the Creative Commons licence, and indicate if changes were made. The images or other third party material in this article are included in the article's Creative Commons licence, unless indicated otherwise in a credit line to the material. If material is not included in the article's Creative Commons licence and your intended use is not permitted by statutory regulation or exceeds the permitted use, you will need to obtain permission directly from the copyright holder. To view a copy of this licence, visit http://creativecommons.org/licenses/by/4.0/.

\section{References}

Allais, M. (1953). Le Comportement de l'Homme Rationnel devant le Risque: Critique de Postulats et Azxiomes de l'Ecole Americaine. Econometrica, 21(4), 503-546. https://doi.org/10.2307/1907921.

Asch, S. E. (1955). Opinions and Social Pressure. Scientific American, 193(5), 31-35.

Ben-Ze'ev, A. (2000). The Subtlety of Emotions. MIT Press.

Ben-Ze'ev, A. (2004). Emotions Are Not Mere Judgments. Philosophy and Phenomenological Research, $68(2), 450-457$.

Ben-Ze'ev, A. (2017). Does Loving Longer Mean Loving More? On the Nature of Enduring Affective Attitudes. Philosophia, 45(4), 1541-1562. https://doi.org/10.1007/s11406-017-9882-4.

Brady, M. S. (2007). Recalcitrant Emotions and Visual Illusions. American Philosophical Quarterly, 44(3), 273-284.

Brady, M. S. (2009). The Irrationality of Recalcitrant Emotions. Philosophical Studies: An International Journal for Philosophy in the Analytic Tradition, 145(3), 413-430. https://doi.org/10.1007/ s11098-008-9241-1.

Cannon, W. B. (1927). The James-Lange Theory of Emotions: A Critical Examination and an Alternative Theory. The American Journal of Psychology, 39(1/4), 106-124. https://doi.org/10.2307/1415404. 
D’Arms, J., \& Jacobson, D. (2003). The Significance of Recalcitrant Emotion (or, Anti-quasijudgmentalism). In A. Hatzimoysis (Ed.), Philosophy and the emotions (pp. 127-146). Cambridge University Press.

Deigh, J. (1994). Cognitivism in the Theory of Emotions. Ethics, 104(4), 824-854. https://doi.org/10. $1086 / 293657$.

Deigh, J. (2000). Nussbaum's Defense of the Stoic Theory of Emotions. Quinnipiac Law Review, 19(2), 293-307.

Deigh, J. (2004). Primitive Emotions. In R.C. Solomon (ed.), Thinking about Feeling. Contemporary Philosophers on Emotions (pp. 9-27). Oxford University Press.

de Waal, F. (2006). Primates and Philosophers: How Morality Evolved. Princeton University Press.

Döring, S. (2014). Why Recalcitrant Emotions Are Not Irrational. In S. Roeser \& C. Todd (Eds.), Emotion and Value (pp. 124-136). Oxford University Press.

Fox, M. W. (1974). Concepts in Ethology: Animal and Human Behavior. University of Minnesota Press.

Goldie, P. (2000). The Emotions: A Philosophical Exploration. Oxford University Press.

Gordon, R. M. (1986). The Passivity of Emotions. The Philosophical Review, 95(3), 371-392.

Greenspan, P. S. (1980). Emotions, Reasons, and 'Self-Involvment'. Philosophical Studies: An International Journal for Philosophy in the Analytic Tradition, 38(2), 161-168. https://doi.org/10.1007/ BF00374332.

Greenspan, P. S. (1988). Emotions and Reasons: An Inquiry into Emotional Justification. Routledge.

Griffiths, P.E. (2004). Is emotion a natural kind? In R.C. Solomon (ed.), Thinking about feeling. Contemporary philosophers on emotions (pp. 233-249). Oxford University Press.

Helm, B. W. (1994). The significance of Emotions. American Philosophical Quarterly, 31(4), 319-331.

Helm, B. W. (2001). Emotional Reason: Deliberation, Motivation, and the Nature of Value. Cambridge University Press.

Hunt, L. (2006). Martha Nussbaum on the Emotions. Ethics, 116(3), 552-577. https://doi.org/10.1086/ 498465.

James, W. (1884). What is an Emotion? Mind, 9(34), 188-205. https://doi.org/10.1093/mind/os-IX.34. 188.

Kahneman, D., \& Tversky, A. (1979). Prospect Theory: An Analysis of Decision Under Risk. Econometrica, 47(2), 263-292. https://doi.org/10.2307/1914185.

Kahneman, D., \& Tversky, A. (1982). The Psychology of Preferences. Scientific American, 246(1), 160173. https://doi.org/10.1038/scientificamerican0182-160.

Kehoe, L. (2016). The Images of Chimps Thrilled Me: Do They Show Evidence of Spirituality in the Wild?, The Guardian, 6 March 2016, from https://www.theguardian.com/science/2016/mar/06/ chimps-more-human-than-we-think, consulted on 20/09/2021.

Lazarus, R. S. (1991). Emotion and Adaption. Oxford University Press.

Lazarus, R.S. and Lazarus, B.N. (1994). Passion and Reason: Making Sense of Your Emotions. Oxford University Press.

LeDoux, J. E. (1996). The Emotional Brain: The Mysterious Underpinnings of Emotional Life. Simon \& Schuster.

Moss, C. J. (2000). Elephant Memories: Thirteen Years in the Life of an Elephant Family (1988). University of Chicago Press.

Nussbaum, M. C. (1994). The Therapy of Desire: Theory and Practice in Hellenistic Ethics. Princeton University Press.

Nussbaum, M. C. (1999). Reply to Papers in Symposium on Nussbaum, The Therapy of Desire. Philosophy and Phenomenological Research, 59(3), 811-819. https://doi.org/10.2307/2653802.

Nussbaum, M. C. (2000). Reply. Quinnipiac Law Review, 19(2), 349-370.

Nussbaum, M. C. (2001). Upheavals of Thought: The Intelligence of Emotions. Cambridge University Press.

Nussbaum, M. C. (2012). The New Religious Intolerance: Overcoming the Politics of Fear in an Anxious Age. The Belknap Press of Harvard University Press.

Nussbaum, M. C. (2013). Political Emotions: Why Love Matters for Justice. The Belknap Press of Harvard University Press.

Nussbaum, M. C. (2016). Anger and Forgiveness: Resentment, Generosity, Justice. Oxford University Press.

Nussbaum, M. C. (2018). The Monarchy of Fear: A Philosopher Looks at Our Political Crisis. Oxford University Press.

Oatley, K. (2004). Emotions: A Brief History. Blackwell. 
Peters, R. S. (1961). Emotions and the Category of Passivity. Proceedings of the Aristotelian Society, 62, $117-134$.

Prinz, J. (2004). Embodied Emotions. In R.C. Solomon (ed.), Thinking about Feeling. Contemporary Philosophers on Emotions (pp. 44-58). Oxford University Press.

Roberts, R. C. (1988). What An Emotion Is: A Sketch. The Philosophical Review, 97(2), 183-209. https://doi.org/10.2307/218526.

Roberts, R. C. (1996). Propositions and Animal Emotion. Philosophy, 71(275), 147-156. https://doi.org/ $10.1017 / \mathrm{s} 0031819100053328$.

Roberts, R. C. (1999). Emotions as Judgments. Philosophy and Phenomenological Research, 59(3), 793798. https://doi.org/10.2307/2653799.

Roberts, R. C. (2003). Emotions: An Essay in Aid of Moral Psychology. Cambridge University Press.

Roberts, R. C. (2009). The Sophistication of Non-Human Emotion. In R. W. Lurz (Ed.), Philosophy of Animal Minds (pp. 218-236). Cambridge University Press.

Scarantino, A. (2010). Insights and Blindspots of the Cognitivist Theory of Emotions. The British Journal for the Philosophy of Science, 61(4), 729-768. https://doi.org/10.1093/bjps/axq011.

Schachter, S., \& Singer, J. E. (1962). Cognitive, Social and Physiological Determinants of Emotional State. Psychological Review, 69(5), 379-399. https://doi.org/10.1037/h0046234

Schloegl, C., \& Fischer, J. (2017). Causal Reasoning in Non-Human Animals. In M. R. Waldmann (Ed.), The Oxford Handbook of Causal Reasoning (pp. 699-715). Oxford University Press.

Seligman, M.E.P. (1975). Helplessness: On Depression, Development, and Death. W.H. Freeman.

Solomon, R. C. (1984). "I Can't Get it Out of My Mind": (Augustine's Problem). Philosophy and Phenomenological Research, 44(3), 405-412. https://doi.org/10.2307/2107693.

Solomon, R. C. (1988). On Emotions as Judgments. American Philosophical Quarterly, 25(2), $183-191$.

Tversky, A., \& Kahneman, D. (1981). The Framing of Decision and the Psychology of Choice. Science, 211(4481), 453-458. https://doi.org/10.1126/science.7455683.

Tversky, A., \& Kahneman, D. (1986). Rational Choice and the Framing of Decisions. The Journal of Business, 59(4), S251-S278. https://doi.org/10.1086/296365.

Williams, B. (1973a). Deciding to Believe. In Id., Problems of the Self. Philosophical Papers 1956-1972 (pp. 136-151). Cambridge University Press.

Williams, B. (1973b). Morality and the Emotions. In Id., Problems of the Self. Philosophical Papers 1956-1972 (pp. 207-229). Cambridge University Press.

Publisher's Note Springer Nature remains neutral with regard to jurisdictional claims in published maps and institutional affiliations. 